\title{
Micromorphological Studies of the Loranthaceae, Phragmanthera capitata (Sprengel) Balle
}

\author{
Franklin Uangbaoje Ohikhena, Olubunmi Abosede Wintola, and Anthony Jide Afolayan
}

Medicinal Plants and Economic Development (MPED) Research Center, Botany Department, University of Fort Hare, Alice, Eastern Cape, South Africa

Correspondence should be addressed to Anthony Jide Afolayan; aafolayan@ufh.ac.za

Received 27 October 2016; Accepted 20 December 2016; Published 23 February 2017

Academic Editor: William K. Smith

Copyright ( $) 2017$ Franklin Uangbaoje Ohikhena et al. This is an open access article distributed under the Creative Commons Attribution License, which permits unrestricted use, distribution, and reproduction in any medium, provided the original work is properly cited.

\begin{abstract}
Phragmanthera capitata (Sprengel) Balle is a mistletoe of the Loranthaceae family that has been explored for its therapeutic properties in folklore for ages. However, there had been an alarming increase in misidentification of species in this family. This may be due in part to the lack of species taxonomic information. Hence, this study wishes to highlight the range of micromorphological features which could complement the information database of this species. Scanning electron, light, and energy dispersive X-ray (EDX) microscopies were used for this study. The result revealed a paracytic type of stomata with mean abaxial and adaxial density of $225.42 \pm 3.67 \mathrm{~mm}^{2}$ and $137.21 \pm 5.65 \mathrm{~mm}^{2}$, respectively, and mean guard cell length of $26.45 \pm 0.02 \mu \mathrm{m}$. Oval-shaped lenticels with a mean length of $34.29 \pm 0.26 \mu \mathrm{m}$ were observed. They were arranged in parallel on the epidermal cells of the abaxial midrib. Densely packed stellate trichomes were revealed on the abaxial epidermis with a density of $63.32 \pm 3.70 \mathrm{~mm}^{2}$. Tracheary elements, which are tightly packed with granules believed to be proteins, were observed in the cross sections of the twig. Deposits chiefly composed of silicon, aluminium, potassium, and iron were recorded in the EDX analysis. This study revealed detailed descriptive micromorphological structures which could serve as a source of information and reference for the taxonomic description of $P$. capitata.
\end{abstract}

\section{Introduction}

Loranthaceae which is the most distributed family of the group of parasitic plants called mistletoe has been plagued with alarming rates of misidentification at the generic and specific levels [1]. This had led to misinformation and misinterpreting by taxonomists and medicinal plants researchers. Misidentification could be as a result of insufficient information on taxonomic characters and overlapping or superimposition of delimitation characters either between the genera or amongst species which is as a result of visible similarities and habits [1].

Anatomical and micromorphological characteristics of leaves, stems, and roots have played important roles in plant taxonomy, especially at the generic and specific levels. Studies in this field have attracted the attention of plant morphologists and systematists to resolve taxonomic conflicts in different groups of plants [2]. The foliar epidermal structure has been one of the most important taxonomic characters in biosystematics and most taxonomic studies are based on the studies of the leaf epidermis. In ultra-structures such as epidermal cells, stomata, and trichomes, their sizes, lengths, distribution, orientation, and frequency are of significant importance in taxonomy as well as phylogeny [3].

Secondary metabolites produced by plants are believed to be stored in various organs including the leaves, stems, and roots. The epidermis of most plants also contains hairs which are functionally classified as glandular or nonglandular trichomes. Glandular trichomes are specialised secretory structures that vary in size, form, location, and function in different plant species [4]. Stomata, glandular trichomes, and nonglandular trichomes that are secretory structures are of scientific interest due to their functional attributes and economic importance in the production/secretion of 


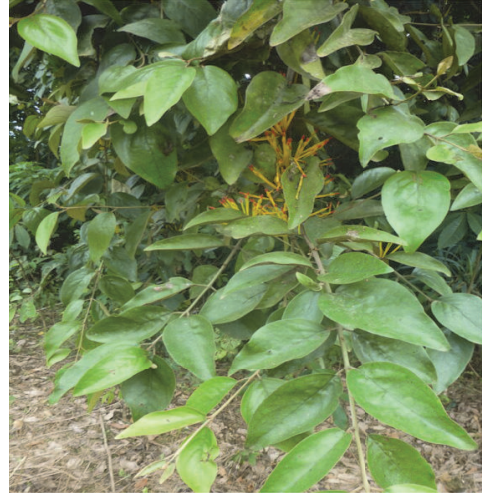

(a)

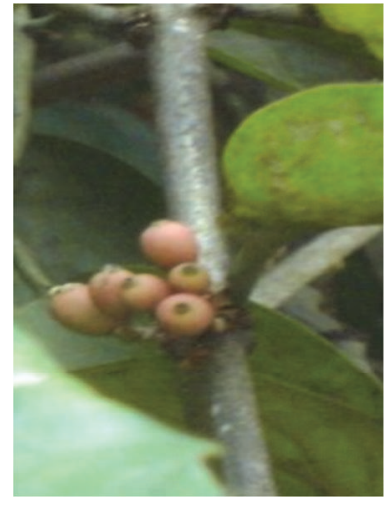

(b)

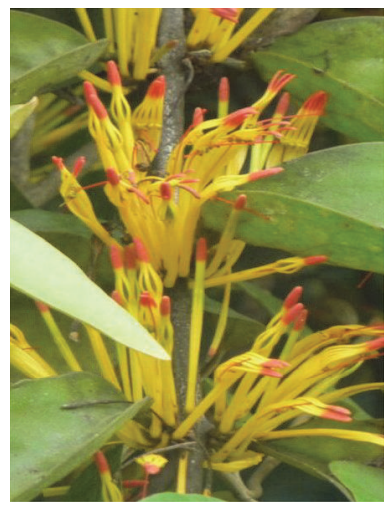

(c)

FIgURE 1: Phragmanthera capitata (Sprengel) Balle showing the leaves (a), seeds (b), and the inflorescence (c) in its natural habitat.

phytochemicals. Glandular trichomes have been reported to possess higher levels of secondary metabolites than those produced from other plant organs [5].

Phragmanthera capitata (Sprengel) Balle (Figure 1) is a species of the Loranthaceae family. It is a woody parasitic shrub, with pendent branches of about $2 \mathrm{~m}$ long. It has a yellow corolla with a pink-red tip and often associated with ants' nests. It grows on trees in secondary jungles, plantations, and bush savannah areas, from Sierra Leone to Western Cameroons, Fernando Po, and extending across the Congo basin to Zaïre, Nigeria, Gabon, Ivory Coast, and Angola [6]. It has been widely used in folklore to treat an array of ailments [6,7]. Despite its folkloric usage, little attention has been given to its micromorphology except in the reports of Ibrahim et al. [1] who gave a preliminary evaluation on the cross sections of the leaves and some other species in the Loranthaceae family. Micromorphological studies are sources of useful information relevant to the taxonomic description of species and also useful in the hands of medicinal plant scientists in comparing and identifying species. This study is therefore aimed at investigating the detailed ultrastructural morphology and elemental compositions of the leaf and twig of $P$. capitata as a source of anatomic information using light and scanning electron microscope (SEM) coupled with energy dispersive X-ray (EDX) spectroscopy.

\section{Materials and Methods}

2.1. Location and Collection of Sample. The leaves of the mistletoe were collected from mature rubber trees in the Rubber Research Institute of Nigeria. The site is located on latitude $6^{\circ} 00^{\prime}-6^{\circ} 15^{\prime} \mathrm{N}$ and longitude $5^{\circ} 30^{\prime}-5^{\circ} 45^{\prime} \mathrm{E}$ and at about $27 \mathrm{~m}$ above sea level. The sample was authenticated by Dr. Emmanuel I. Aigbokhan at the Plant Biology and Biotechnology Department, University of Benin (UNIBEN), and a voucher specimen (UBH10284) was deposited at the UNIBEN herbarium.

2.2. Light Microscopy. Light microscopic examinations of the leaves were done by obtaining peels from the adaxial and abaxial surfaces of matured fresh leaves. The peels were placed on glass slides with 1-2 drops of nile blue sulfate stain, covered, and observed under a Zeiss light microscope. The photomicrographs were taken with a digital camera (DCM $510,5 \mathrm{M}$ pixels, CMOS chip) that was fitted to the light microscope.

2.3. Scanning Electron Microscopy and Energy Dispersive XRay Spectroscopy. Fresh leaves and stems (transverse) were cut into segments of $4-6 \mathrm{~mm}$ in length and fixed in $6 \%$ glutaraldehyde with $\mathrm{pH} 7.3$ for $12 \mathrm{~h}$. The sections were rinsed with $0.05 \mathrm{M}$ sodium cacodylate buffer ( $\mathrm{pH}$ 7.5). Each sample was later rinsed in distilled water and dehydrated in a graded series of ethanol $10-100 \%$ for 20 min per rinse. The sections were dried in a Hitachi HCP- 2 critical point dryer and mounted on aluminium stubs with double-sided carbon coated sputter coating with gold palladium (Elko IB-3 Ion Coater). The samples were examined at varying magnifications using JEOL (JSM-6390LV) scanning electron microscope (SEM) that was operated at $10-15 \mathrm{kV}$ accelerated voltage. The energy dispersive X-ray spectroscopy (EDX) involved both fixing and dehydration procedure as in SEM, while the elemental analysis was done using energy dispersive X-ray analyser which was coupled to SEM, manufactured by Thermo Electron Corporation, 6733B-IUUSN, USA. The Noran system six software was used for imaging.

\section{Result}

\subsection{Foliar Micromorphology}

3.1.1. Stomata. The photomicrographs of the light and scanning electron microscope of $P$. capitata leaf surfaces revealed a paracytic type of stomata. They are amphistomatically distributed but are more on the abaxial surface (Figures 2 and 3). They are randomly arranged on both epidermal surfaces and are mostly conspicuous and visible on the adaxial surface. The abaxial surface stomata were mostly covered by a mass of trichomes (Figures 2 and 3 ) and only made visible when the trichome withers or breaks away (which was made possible by prolonged soaking of the leaf in absolute ethanol after fixation) (Figure 3(b)). Most of the stomata observed on 


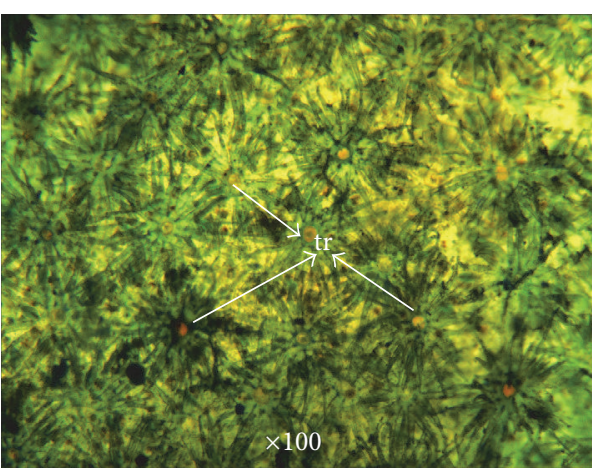

(a)

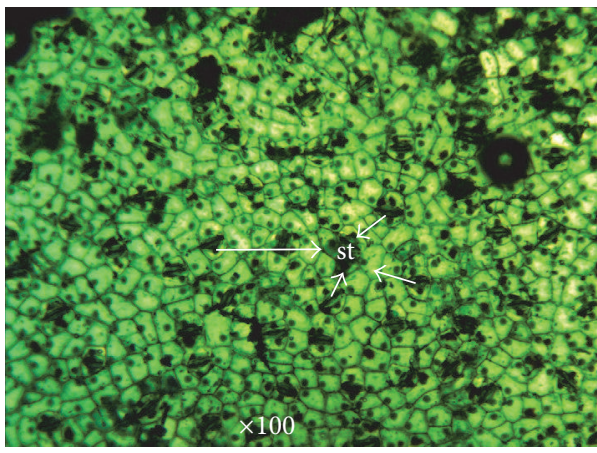

(c)

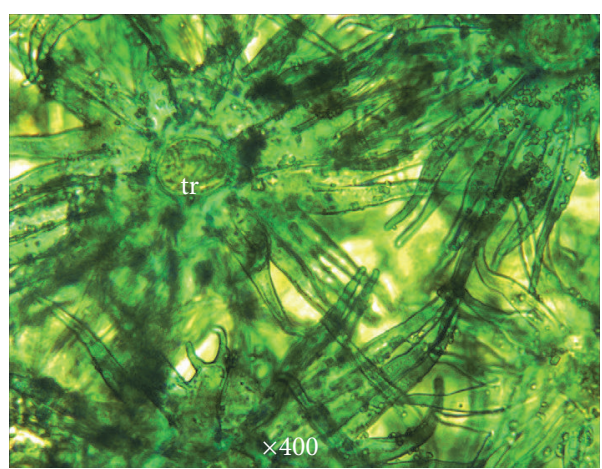

(b)

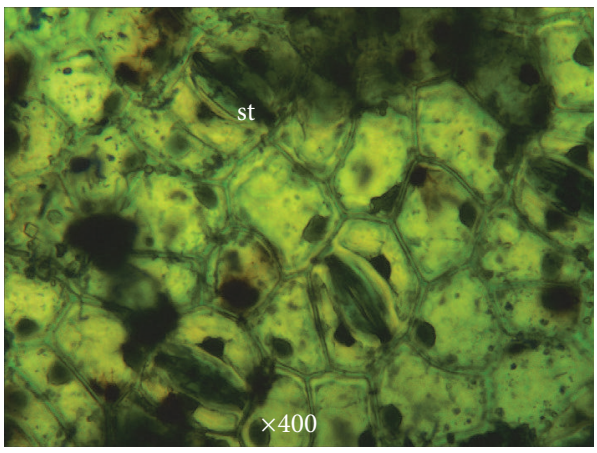

(d)

Figure 2: Photomicrographs of the light microscopy of $P$. capitata. $(\mathrm{a}, \mathrm{b})$ Abaxial epidermis showing the stellate trichomes (tr) at $\times 100$ and $\times 400$, respectively; $(c, d)$ represent the adaxial epidermis showing the paracytic stomata $(s t)$ at $\times 100$ and $\times 400$, respectively.

the adaxial surface were fully opened while the few sighted on the abaxial surface were tightly shut. The mean adaxial stomata density was $137.21 \pm 5.65 \mathrm{~mm}^{2}$ with pore length of $16.32 \pm 2.20 \mu \mathrm{m}$ when fully opened. The guard cells length of both surfaces was $26.45 \pm 0.02 \mu \mathrm{m}$ while the abaxial stomata density was $225.42 \pm 3.67 \mathrm{~mm}^{2}$. Oval-shaped lenticels (34.29 \pm $0.26 \mu \mathrm{m})$ were observed arranged in parallel on the abaxial midrib of the leaf (Figure 4).

3.1.2. Trichomes. This study revealed densely packed stellate trichomes with globular center tapering towards the tips, often overlapping themselves on the abaxial surface (Figures 2-4) and completely masking the underlying epidermal cells and stomata. The abaxial trichomes were a bit raised from the epidermal surface. There was a rare sighting of trichomes on the adaxial surface "(Figures 2(c), 2(d), 3(d), and 3(e)) and could not be ascertained if they were really adaxial trichomes or break away from the abaxial surface in this study. The observed adaxial stellate trichomes were more fixed to the cuticle as compared to the ones observed on the abaxial surface that were a bit raised from the cuticle. The mean trichome density and length (diagonal) in the abaxial surface were $63.32 \pm 3.70 \mathrm{~mm}^{2}$ and $193.73 \pm 16.19 \mu \mathrm{m}$, respectively, while the mean adaxial trichome length was $140.91 \pm 15.74 \mu \mathrm{m}$ and the mean density could not be determined because they were scarcely available.
3.2. Stem (Twig) Micromorphology. The stem was characterised by unusual xylem conducting cells known as graniferous tracheary elements. The tracheary elements were tightly packed with grains of size $5.11 \pm 0.48 \mu \mathrm{m}$ (Figure 5).

3.3. Energy Dispersive X-Ray (EDX) Spectroscopy. Results of the $\mathrm{X}$-ray microanalyses of some points on the leaf epidermis, a crystal deposit, and the grains in the xylem of $P$. capitata showed the specific spectra of the following elements: carbon $(\mathrm{C})$, oxygen $(\mathrm{O})$, calcium $(\mathrm{Ca})$, sulphur $(\mathrm{S})$, sodium $(\mathrm{Na})$, potassium $(\mathrm{P})$, silicon $(\mathrm{Si})$, iron $(\mathrm{Fe})$, zinc $(\mathrm{Zn})$, magnesium $(\mathrm{Mg})$ and aluminium $(\mathrm{Al})$, nitrogen $(\mathrm{N})$, and white gold (AU) were assumed to be derived from the spur plating (Figures 6 and 7). The percentage atomic quantification of the elements as revealed by the EDX spectroscopy was recorded (Table 1). Carbon and oxygen are the only two elements (aside from gold) in all the parts scanned. Aluminium and silicon were found on both surfaces of the leaf but were the major constituents of the crystal deposit. Nitrogen was detected on the abaxial surface $(6.61 \pm 2.57 \%)$, the crystal $(0.3 \pm 0.07 \%)$, and the granules $(6.18 \pm 6.68 \%)$.

\section{Discussion}

Variations in frequency, types, distribution, and arrangement of stomata are features which serve taxonomic importance at 


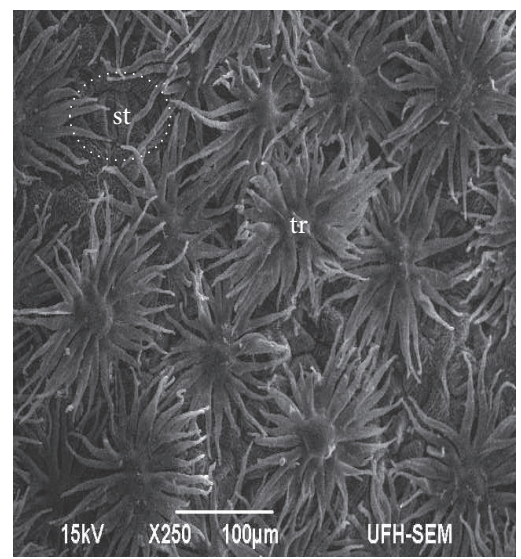

(a)

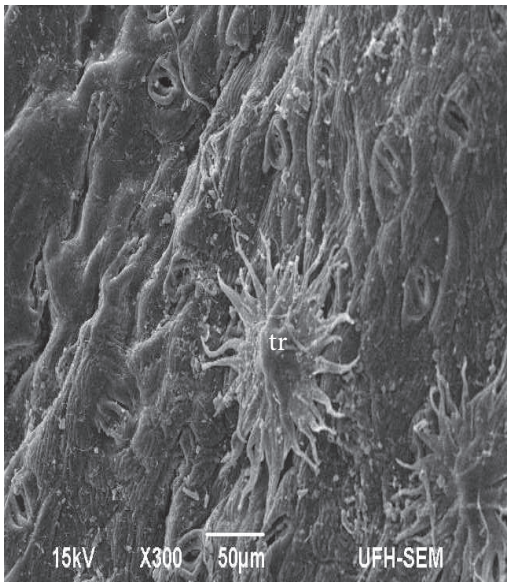

(d)

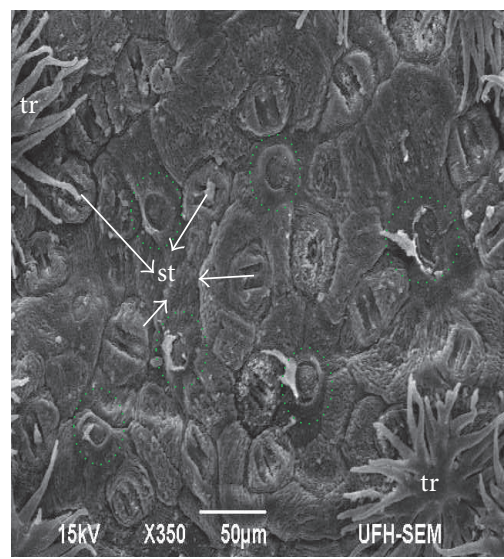

(b)

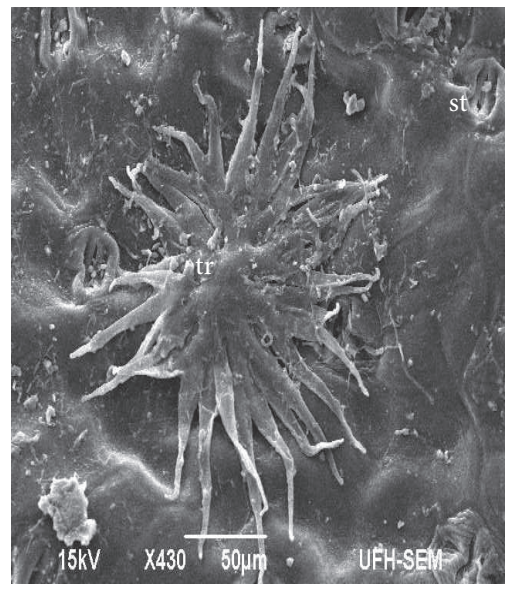

(e)

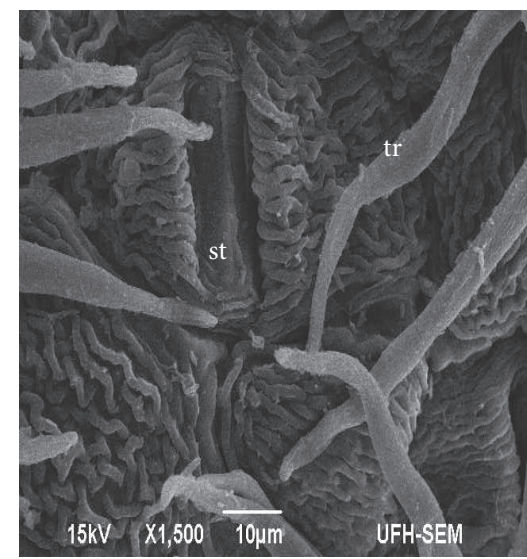

(c)

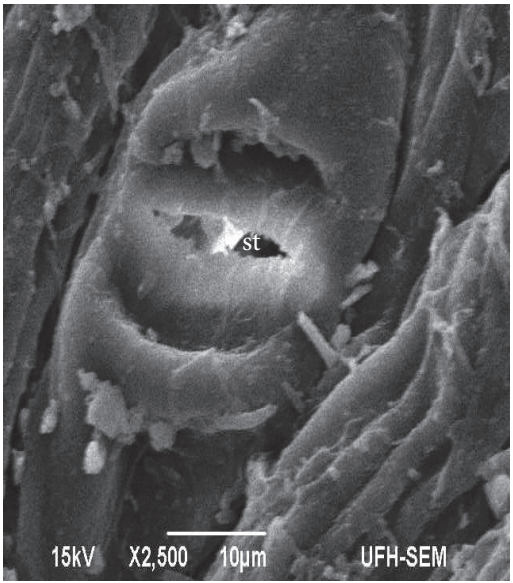

(f)

FIGURE 3: SEM photomicrographs of P. capitata. (a)-(c) are the abaxial epidermis with (a) showing the stellate trichomes (tr) and (b) and (c) revealing the dense stomata (green circles are the point of trichomes detachment) at varying magnifications. (d)-(f) are the adaxial epidermis showing the stomata (st) and a trichome at varying magnifications.

TAble 1: Percentage atomic compositions of the elements in P. capitata leaf surfaces as shown by the EDX spectroscopy.

\begin{tabular}{|c|c|c|c|c|}
\hline \multirow{2}{*}{ Elements } & \multicolumn{4}{|c|}{ Atom (\%) } \\
\hline & Abaxial & Adaxial & Crystal & Granules \\
\hline Carbon & $62.52 \pm 1.03$ & $55.81 \pm 1.24$ & $6.73 \pm 0.86$ & $34.94 \pm 4.03$ \\
\hline Oxygen & $23.67 \pm 1.03$ & $29.18 \pm 0.92$ & $54.77 \pm 0.78$ & $40.14 \pm 3.60$ \\
\hline Sodium & 0 & 0 & $0.30 \pm 0.07$ & 0 \\
\hline Nitrogen & $6.61 \pm 2.57$ & 0 & 0 & $6.18 \pm 6.83$ \\
\hline Calcium & $1.23 \pm 0.11$ & 0 & $0.11 \pm 0.04$ & 0 \\
\hline Potassium & $0.02 \pm 0.04$ & 0 & $1.51 \pm 0.05$ & 0 \\
\hline Aluminum & $0.24 \pm 0.05$ & $0.99 \pm 0.07$ & $13.86 \pm 0.18$ & 0 \\
\hline Silicon & $0.34 \pm 0.05$ & $7.62 \pm 0.18$ & $16.11 \pm 0.20$ & 0 \\
\hline Sulfur & $0.20 \pm 0.08$ & 0 & $0.02 \pm 0.07$ & $0.47 \pm 0.61$ \\
\hline Iron & $0.22 \pm 0.08$ & 0 & $2.07 \pm 0.21$ & 0 \\
\hline Zinc & 0 & 0 & $0.21 \pm 0.17$ & 0 \\
\hline Magnesium & 0 & 0 & $0.43 \pm 0.07$ & 0 \\
\hline Gold & $4.87 \pm 0.58$ & $6.40 \pm 0.92$ & $3.67 \pm 0.53$ & $18.28 \pm 3.82$ \\
\hline
\end{tabular}




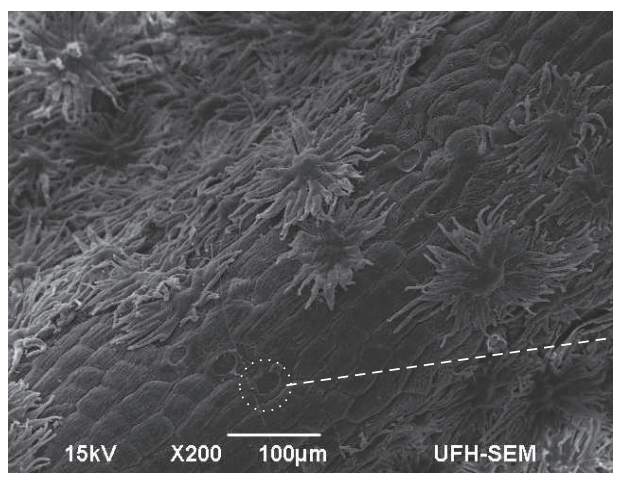

(a)

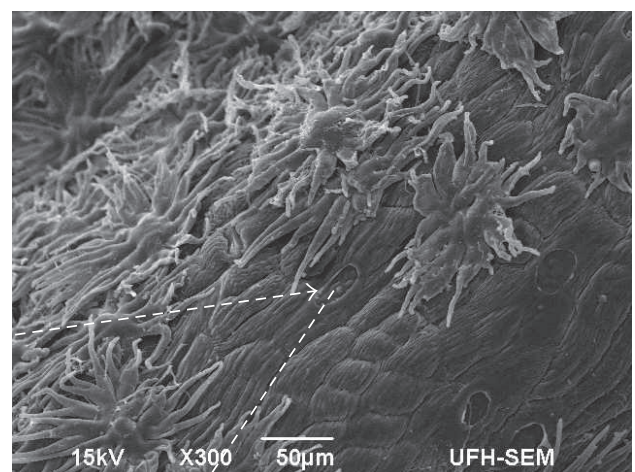

(b)

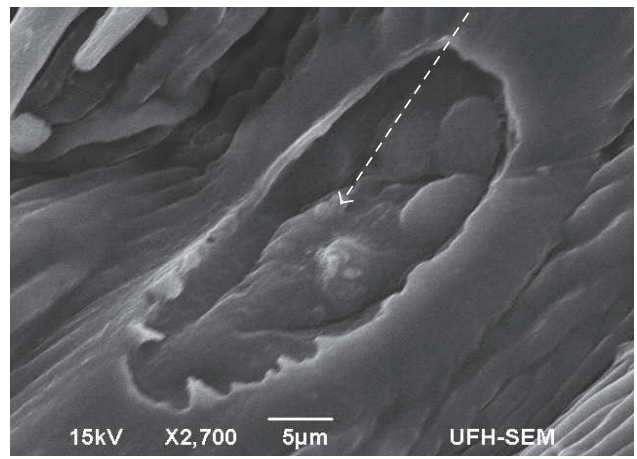

(c)

FIGURE 4: SEM photomicrographs; (a)-(c) showing lenticel on the midrib of the abaxial surface at different magnifications.

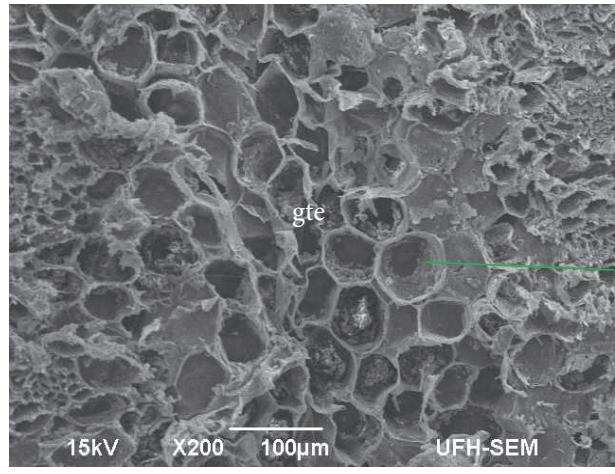

(a)

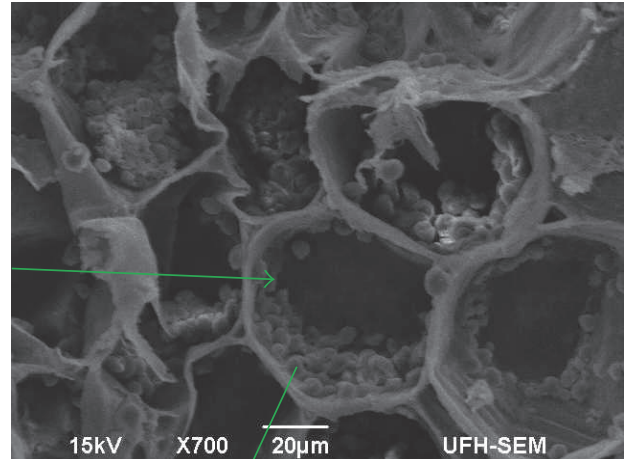

(b)

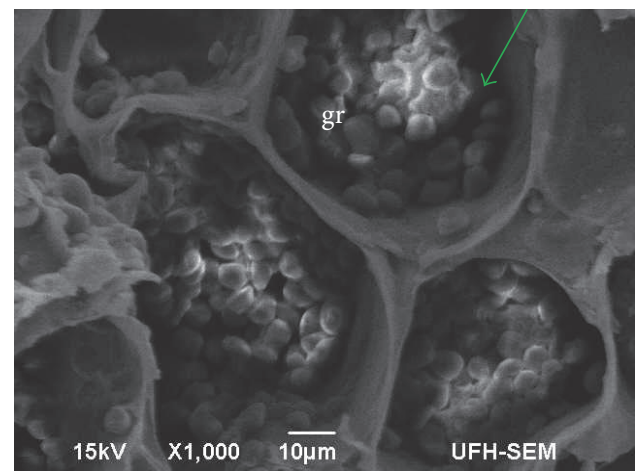

(c)

FIGURE 5: SEM photomicrograph of a transverse section of graniferous tracheary elements (gte) showing the grains (gr) at varying magnifications $(\mathrm{a}-\mathrm{c})$. 

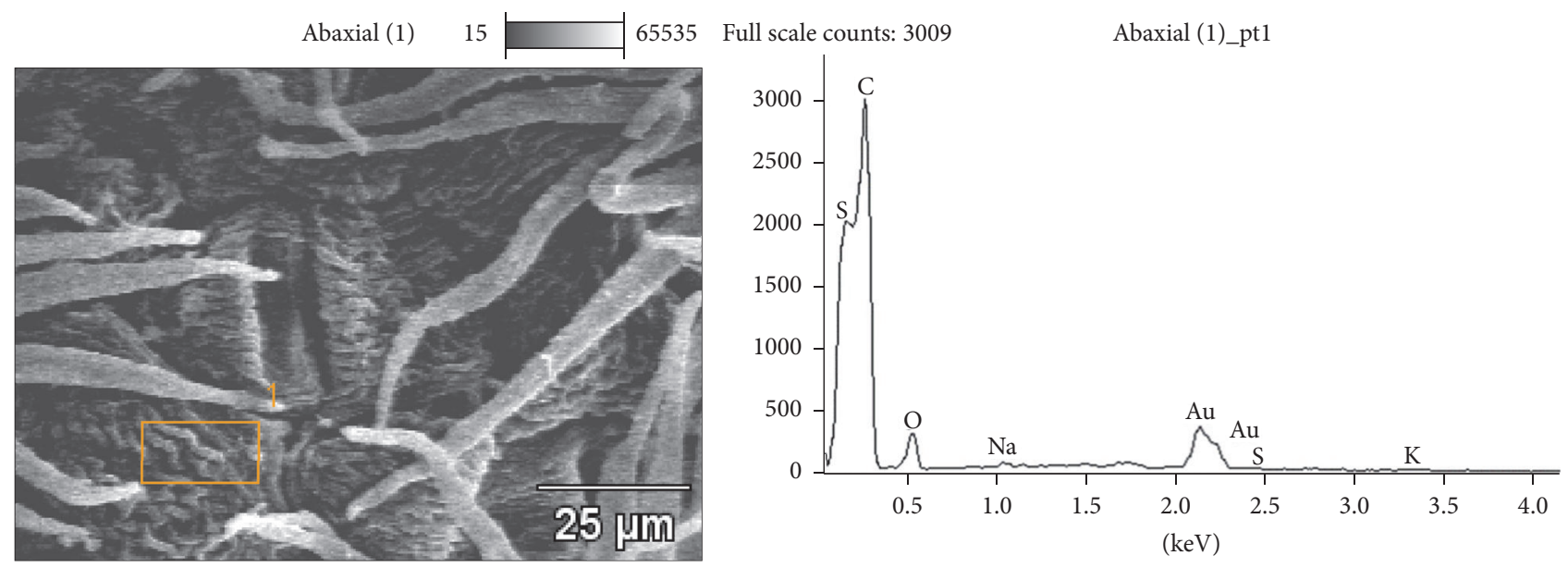

(a)

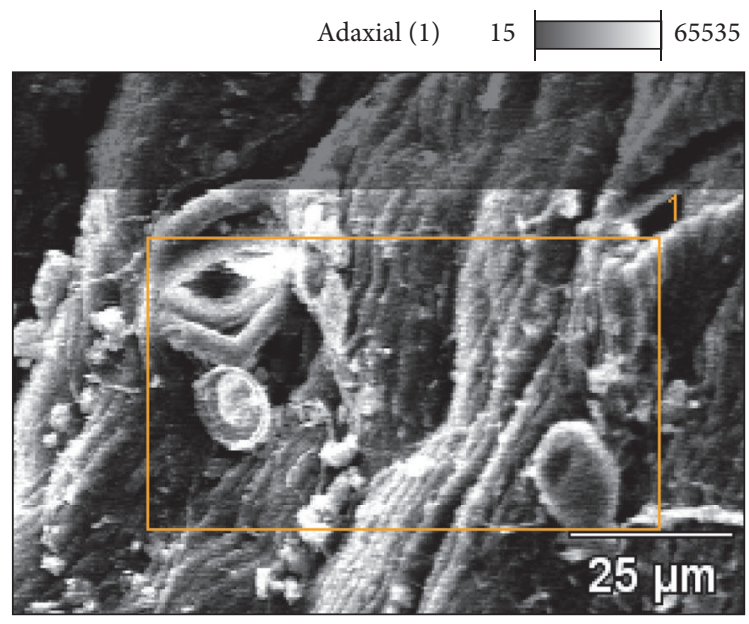

Full scale counts: 601

Adaxial (1)_pt1

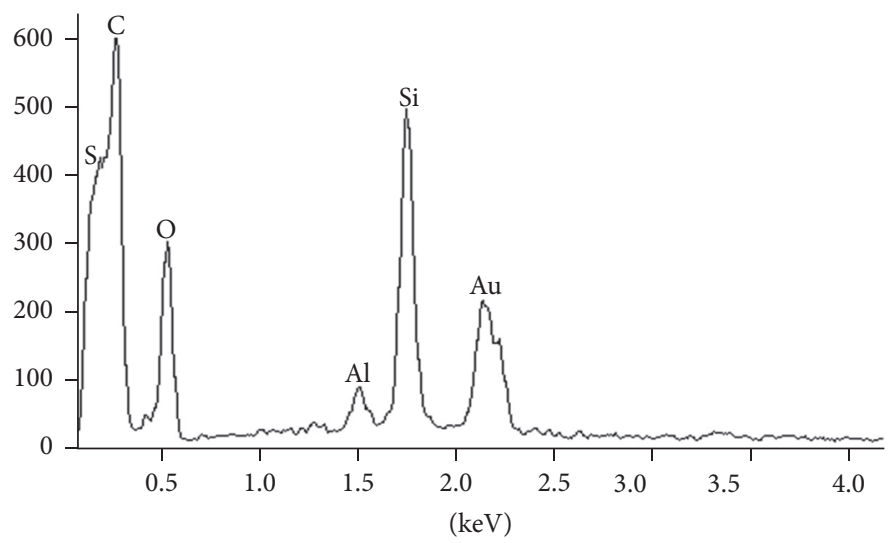

(b)

FIGURE 6: EDX photomicrographs and spectra of the abaxial (a) and adaxial epidermis (b).

the generic level of classification [3]. Stomata are microscopic openings on the surfaces of plant leaves that allow for the easy passage of water vapour, carbon dioxide, and oxygen. The opening of the stomata increases transpiration rate which in turn increases absorption of water and nutrient. P. capitata being a hemiparasite must have a 2 -5-fold transpiration rate higher than its host because it must compete with the host branches for water and/or nutrient [8]. Therefore, in achieving this, the adaxial stomata of $P$. capitata were observed to be kept opened (Figures 3(d)-3(f)). Stomata are closed mostly at night and when this happens, the transpiration rate drops and the water/nutrient intake reduces. In overcoming this, $P$. capitata was further furnished with lenticels on the leaf's midrib (Figure 4). Lenticels work in a similar way as the stomata but are triggered at night when most/all of the stomata are closed. Though lenticels are commonly found in stems and fruits of plants, these were observed on the midribs of the leaves. This to the best of our knowledge is the first report of foliar lenticels in Loranthaceae. This could provide addition information on the foliar structure of this plant.
Scientific interest in leaf trichomes is based on their functions which include lowering of leaf temperature, increase in tolerance to freeze, storage of phytochemicals, protection of the inner tissues from UV radiations from sun, water retention, protection against insect herbivores and airborne fungi [9], and a keystone in delimitation of species in taxonomic studies [3]. The densely packed stellate trichomes observed in P. capitata may serve the function of mechanical protection against insect herbivores that use the leaves as a nest. This is in support of Dalin et al. [10] report that there is a positive correlation of herbivory with increased trichome density. It is also suggested that the trichomes may function as a temperature buffer in reducing the amount of water lost during transpiration. The compactly packed stellate trichomes observed in this study could serve as a source of taxonomic information in identifying this species from the rest of the family and/or genus (Loranthaceae and/or Phragmanthera), because none of the reported trichomes in the Loranthaceae species studied by Ibrahim et al. [1] aside P. capitata was stellate. The adaxial cuticle is less striated and closely packed 


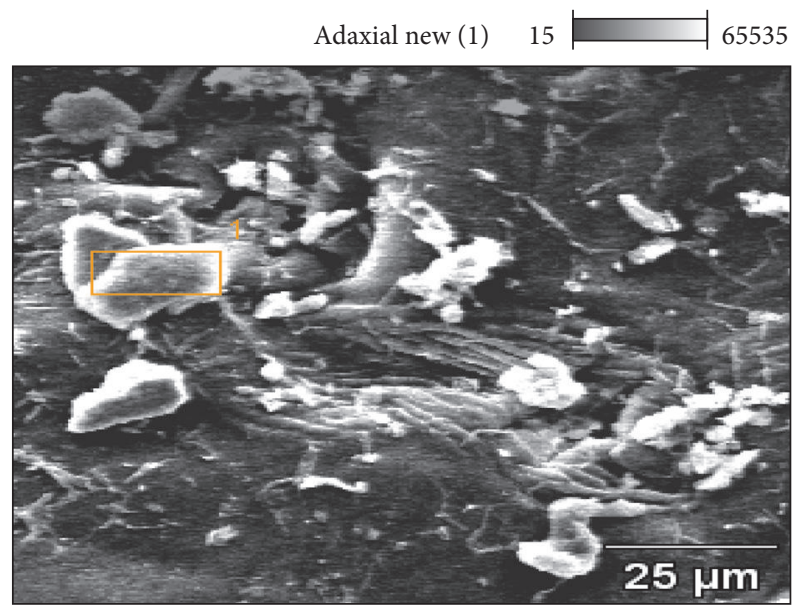

Full scale counts: 1349

Abaxial new (1)_pt1

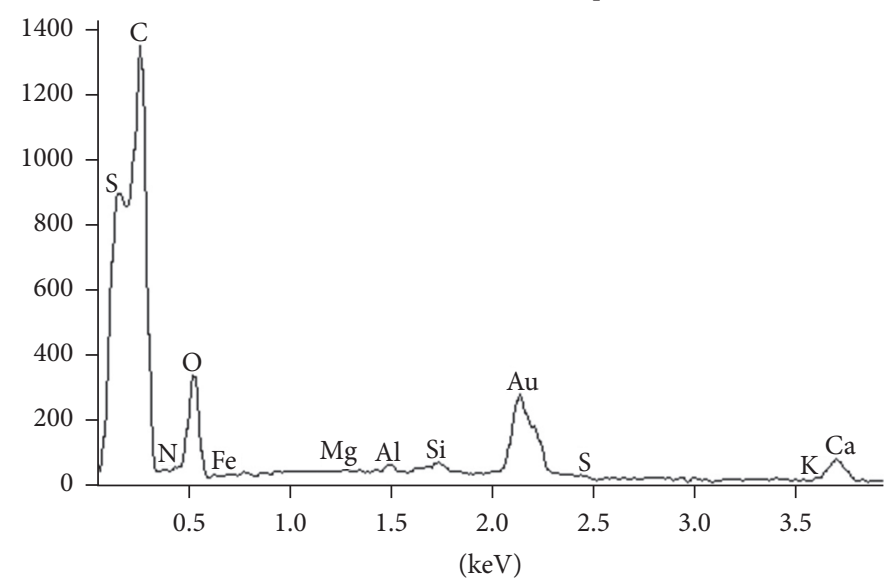

(a)

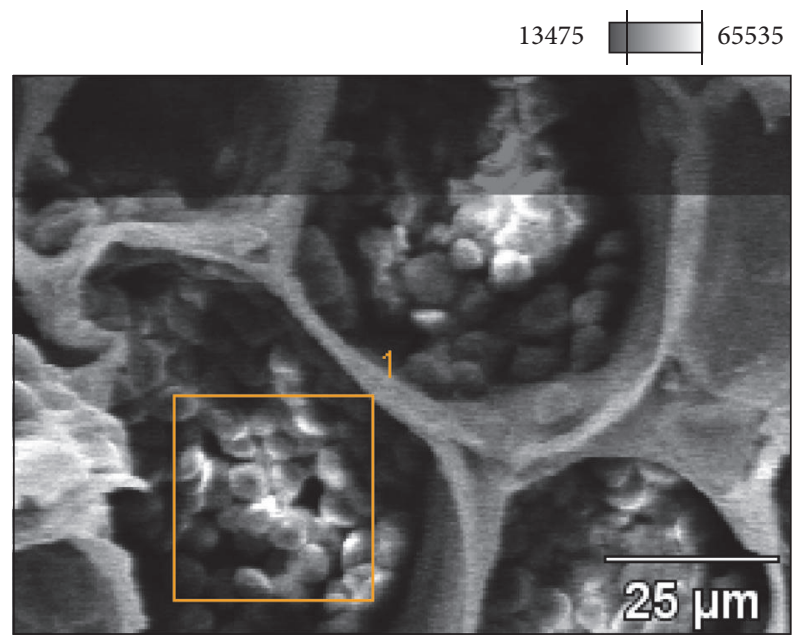

Full scale counts: 62

Stem (1)_pt1

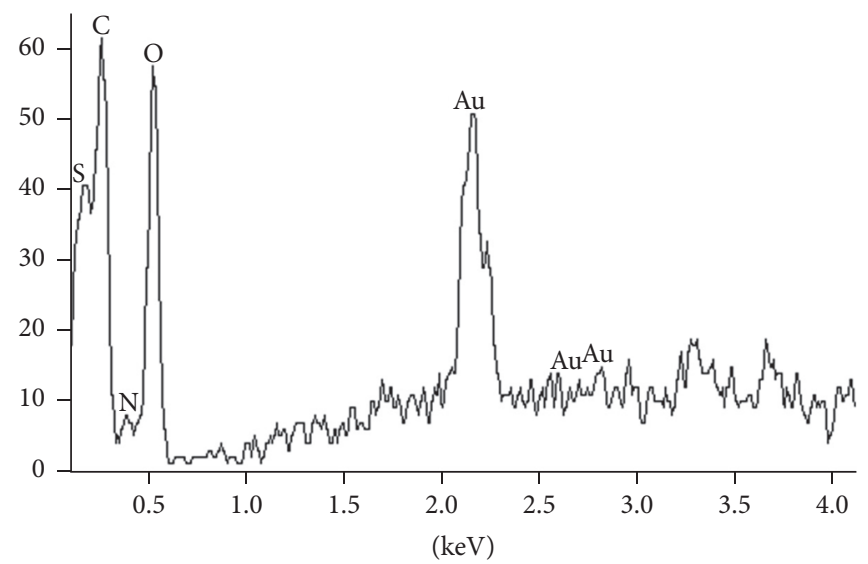

(b)

FIGURE 7: EDX photomicrographs and spectra of the crystal deposit (a) and granules in the tracheary elements (b).

(and appears smooth at low magnification) than the abaxial surface that is curly/spiral and less compact. This could be the reason why the trichomes were concentrated at the abaxial surface to reduce transpiration. Concrete evidence from SEM micrograph alone cannot provide information required for the production of phytocompounds in plants [11] and since no clear-cut glandular trichomes were observed in this study, it is believed that they are produced and stored by other specialised cells.

The SEM result of the xylem revealed numerous tracheary elements that were filled with grains which in accordance with Fineran [12] and Hawksworth and Wiens [13] are proteins as against the starch grains found in most plants. Though the function of these graniferous tracheary elements is not fully known, early works by Benson 1910 as reported by Fineran [12] suggested that they serve the function of both the phloem and the xylem conducting elements and called them "phloeotracheides." It was the research work of Fineran that later classified these cells as graniferous tracheary elements as it is known till date. These cells were only believed to exist in the haustorium of the root hemiparasites but in 1984, the first report of these elements in the stem and haustorium of aerial hemiparasitic plants was recorded [12]. These graniferous tracheary elements were believed to be storage cells; some also believed that they may withdraw nutrients from the host by creating an osmotic gradient towards the parasite. The granules, however, are assumed to withdraw substances from the host by creating an osmotic gradient or may be the products of the process and serve as reserved nutrient [12]. These grains may serve taxonomic importance in delimitation amongst other parasitic angiosperms because they are only found in the Santalaceae and Loranthaceae mistletoes. Other families of parasitic angiosperms contain starch grains that are only morphologically alike with the protein grains [13].

This study showed that the xylem of $P$. capitata may not only conduct water but also absorb nutrients from the host, therefore, supporting the suggestion of Hawksworth and Wiens [13] that the photosynthate from hemiparasites is scarcely used as the parasites depend mostly on the nutrients 
absorbed from the host. This could explain why chemical compositions of a parasitic plant are dependent on the host. In addition, the presence of nitrogen $(6.18 \pm 6.83 \%)$ and sulphur $(0.47 \pm 0.61 \%)$ in the EDX analysis (Figure 7 and Table 1) however suggests that the granules may be made up of proteins as earlier stated.

Some crystal deposits were observed on the leaf surfaces (Table 1). Crystals have been classified as crystal sand, druses, raphides, styloid, and prism [14]. The criterion for their classification is not fully understood; hence, the crystal deposits in $P$. capitata could not be singled to any of them. It is assumed that crystal deposits on leaf could give it antiherbivory characteristics and that these crystals are usually secreted as a defence mechanism by trichomes on the leaf surface of most plant species [9]. Crystals are also believed to play roles in cellular ion balance and tissue rigidity and support and in detoxification of harmful metals [15].

The major elements on the crystals were Si (16.11 \pm $0.20 \%), \mathrm{Al}(13.86 \pm 0.18 \%), \mathrm{Fe}(2.07 \pm 0.212)$, and $\mathrm{Mg}$ $(1.51 \pm 0.05)$. This is in conformity with the report of Aliero et al. [16]. Silicon (Si) is laid down on leaf surface as spines and other sharp bodies, known as phytoliths, making leaves abrasive and their foliage indigestible to herbivores. Previous studies on $\mathrm{Si}$ defences found that closely related species may have similar levels of $\mathrm{Si}$ in the leaves but differ markedly in abrasiveness; hence, it functions for delimitation of species in plant taxonomy [17]. Aluminium is regarded as a toxic element but was found in high amount in the crystal deposits on the leaf. The effect of $\mathrm{Al}$ in plants is reduced root development and reduction in other metals (mostly $\mathrm{Ca}$ and $\mathrm{K}$ ) presence and utilisation [18]. This may be responsible for the low amount of $\mathrm{Ca}$ and $\mathrm{K}$ observed on the leaf as detected by the EDX (Table 1). This may suggest that $P$. capitata can survive in a wide range of hosts and can serve in the detoxification of $\mathrm{Al}$ as it absorbs it from the host and excretes it to the surface which can easily be washed off by other environmental factors.

Calcium is assumed to initiate closer of the stomata and hence plays a role in transduction [19]. Calcium was recorded on the abaxial surface $(1.23 \pm 0.11 \%)$ and little quantity in the crystal $(0.11 \pm 0.04 \%)$ of $P$. capitata (Table 1$)$; hence, this could suggest why the stomata observed on the abaxial surface in the SEM photomicrographs were tightly closed while the adaxial surface devoid of Ca deposits had most of its stomata fully opened (Figures 3(d)-3(f)).

\section{Conclusion}

Being a plant widely utilised in alternative medicine, the tiniest information which could be useful in identifying it is of most prerogative. This study has highlighted detailed descriptive information of the micromorphological structures of $P$. capitata. The presence of the tightly packed stellate trichomes, the stomata type, density, distribution, and length, the lenticels on the midrib, and the different textural cuticle found on the epidermis could be useful in providing taxonomic information and could also serve as a database for future references of the species. The presence of the protein granules in the tracheary elements which is a rare feature found only in selected parasitic plant families could also be of great relevance in the field of taxonomy and systematics.

\section{Competing Interests}

The authors declare that there are no competing interests on this work.

\section{Acknowledgments}

Authors appreciate the financial support of the Govan Mbeki Research Development Center, University of Fort Hare, South Africa, and the Rubber Research Institute of Nigeria, Iyanomo.

\section{References}

[1] J. A. Ibrahim, O. F. Kunle, and A. E. Ayodele, "Anatomical features of the transverse sections of the leaves of loranthaceae in Nigeria," International Journal of Pharmacognosy and Phytochemical Research, vol. 7, no. 3, pp. 489-501, 2015.

[2] M. A. Sonibare, T. A. Oke, and M. O. Soladoye, "A pharmacobotanical study of two medicinal species of Fabaceae," Asian Pacific Journal of Tropical Biomedicine, vol. 4, no. 2, pp. 131-136, 2014.

[3] S. Albert and B. Sharma, "Comparative foliar micromorphological studies of some Bauhinia (Leguminosae) species," Turkish Journal of Botany, vol. 37, no. 2, pp. 276-281, 2013.

[4] R. E. Robles-Zepeda, E. Lozoya-Gloria, M. G. López, M. L. Villarreal, E. Ramírez-Chávez, and J. Molina-Torres, "Montanoa tomentosa glandular trichomes containing kaurenoic acids chemical profile and distribution," Fitoterapia, vol. 80, no. 1, pp. 12-17, 2009.

[5] A. A. Badmus and A. J. Afolayan, "The foliar micromorphology of Arctotis arctotoides (L.f.) O. Hoffm," Journal of Medicinal Plants Research, vol. 4, no. 16, pp. 1643-1646, 2010.

[6] L. P. Takem, N. P. Abe, and J. O. Ogbonna, "Assessment of glycaemic property of Phragmanthera capitata," International Journal of Pharmacy and Pharmaceutical Sciences, vol. 4, no. 4, pp. 1-8, 2015.

[7] O. T. Ogunmefun, T. R. Fasola, A. B. Saba, and O. A. Oridupa, "The ethnobotanical, phytochemical and mineral analyses of Phragmanthera Incana (Klotzsch), a species of mistletoe growing on three plant hosts in South-western Nigeria," International Journal of Biomedical Science, vol. 9, no. 1, pp. 33-40, 2013.

[8] D. Y. Okubamichael, M. E. Griffiths, and D. Ward, "Host specificity, nutrient and water dynamics of the mistletoe Viscum rotundifolium and its potential host species in the Kalahari of South Africa," Journal of Arid Environments, vol. 75, no. 10, pp. 898-902, 2011.

[9] A. O. T. Ashafa, D. S. Grierson, and A. J. Afolayan, "Foliar micromorphology of Felicia muricata Thunb., a South African medicinal plant," Pakistan Journal of Biological Sciences, vol. 11, no. 13, pp. 1713-1717, 2008.

[10] P. Dalin, J. A. Ågren, C. Björkman, P. Huttunen, and K. Kärkkäinen, "Leaf trichome formation and plant resistance to herbivory," in Induced Plant Resistance to Herbivory, A. Schaller, Ed., pp. 89-105, Springer Science+Business Media, Dordrecht, The Netherlands, 2008. 
[11] A. J. Afolayan and J. J. Meyer, "Morphology and ultrastructure of secreting and nonsecreting foliar trichomes of Helichrysum aureonitens(Asteraceae)," International Journal of Plant Sciences, vol. 156, no. 4, pp. 481-487, 1995.

[12] B. A. Fineran, "Graniferous tracheary elements in haustoria of root parasitic angiosperms," The Botanical Review, vol. 51, no. 4, pp. 389-441, 1985.

[13] F. G. Hawksworth and D. G. Wiens, Dwarf Mistletoe: Biology, Pathology and Systematics, Agricultural Handbook 709, United States Department of Agriculture, Forest Service, Washington, DC, USA, 1996.

[14] E. E. Farmer, Leaf Defence, Oxford University Press, Oxford, UK, 2014.

[15] W. M. Otang, D. S. Grierson, and R. Ndip, "Foliar micromorphology of Gasteria bicolor haw. (Asphodelaceae) from South Africa," African Journal of Traditional, Complementary and Alternative Medicines, vol. 11, no. 4, pp. 71-76, 2014.

[16] A. A. Aliero, D. S. Grierson, and A. J. Afolayan, "The foliar micromorphology of Solanum pseudocapsicum," Flora: Morphology, Distribution, Functional Ecology of Plants, vol. 201, no. 4, pp. 326-330, 2006.

[17] S. E. Hartley, R. N. Fitt, E. L. McLarnon, and R. N. Wade, "Defending the leaf surface: intra- and inter-specific differences in silicon deposition in grasses in response to damage and silicon supply," Frontiers in Plant Science, vol. 6, article no. 35, 2015.

[18] T. Mossor-Pietraszewska, "Effect of aluminium on plant growth and metabolism," Acta Biochimica Polonica, vol. 48, no. 3, pp. 673-686, 2001.

[19] S. Gilroy, M. D. Read, and A. J. Trewavas, "Role of calcium in signal transduction of Commelina guard cells," The Plant Cells, American Society of Plant Physiologists, vol. 3, pp. 333-344, 2011. 

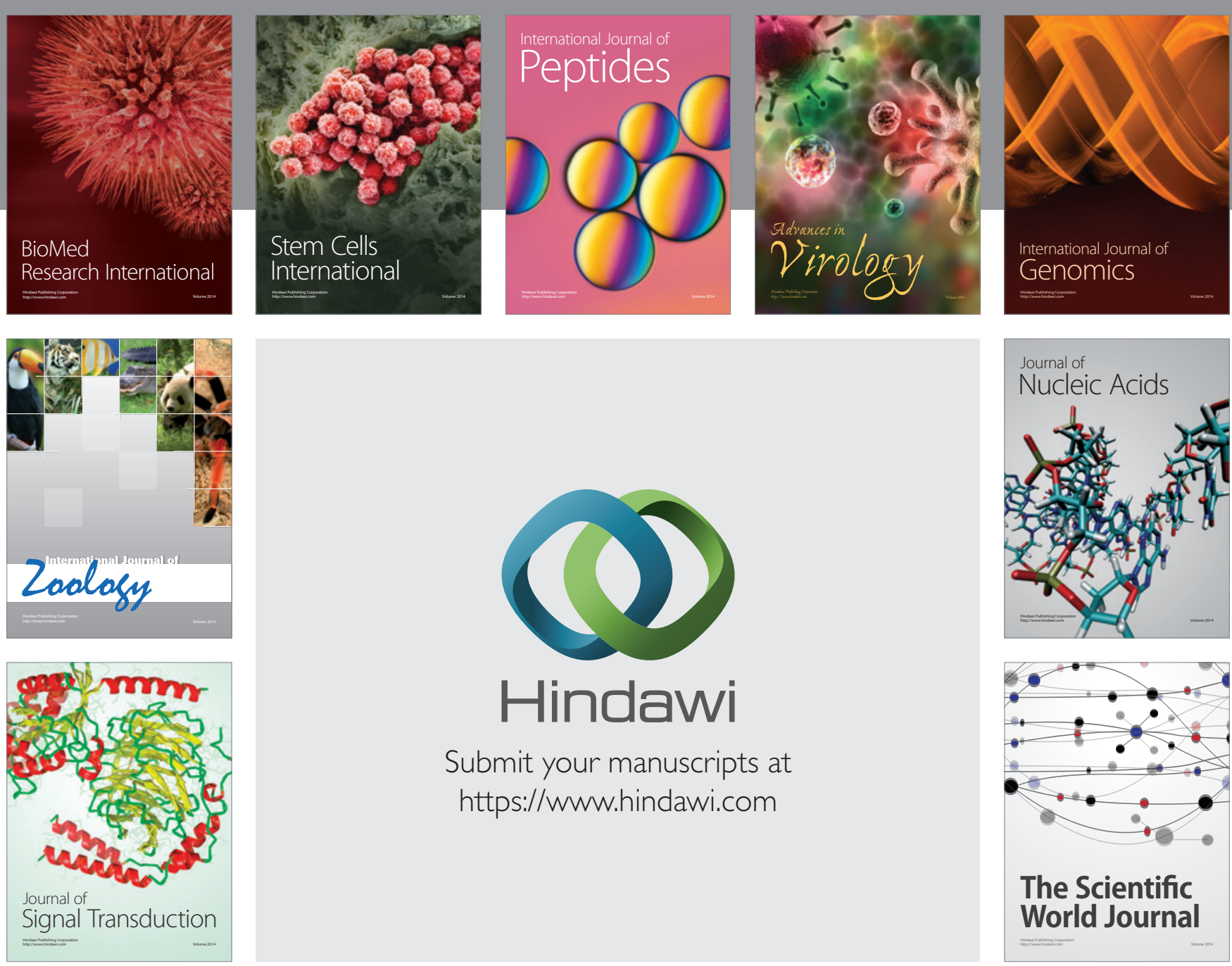

Submit your manuscripts at

https://www.hindawi.com
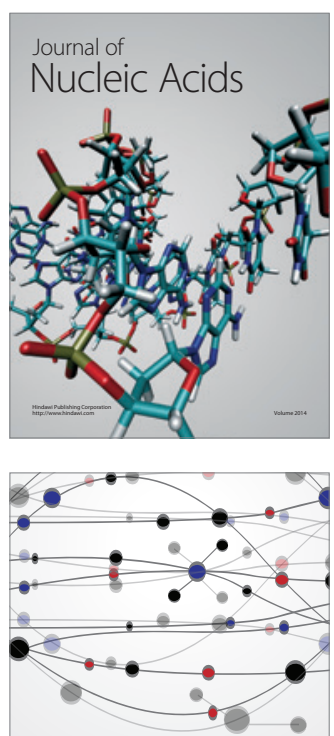

The Scientific World Journal
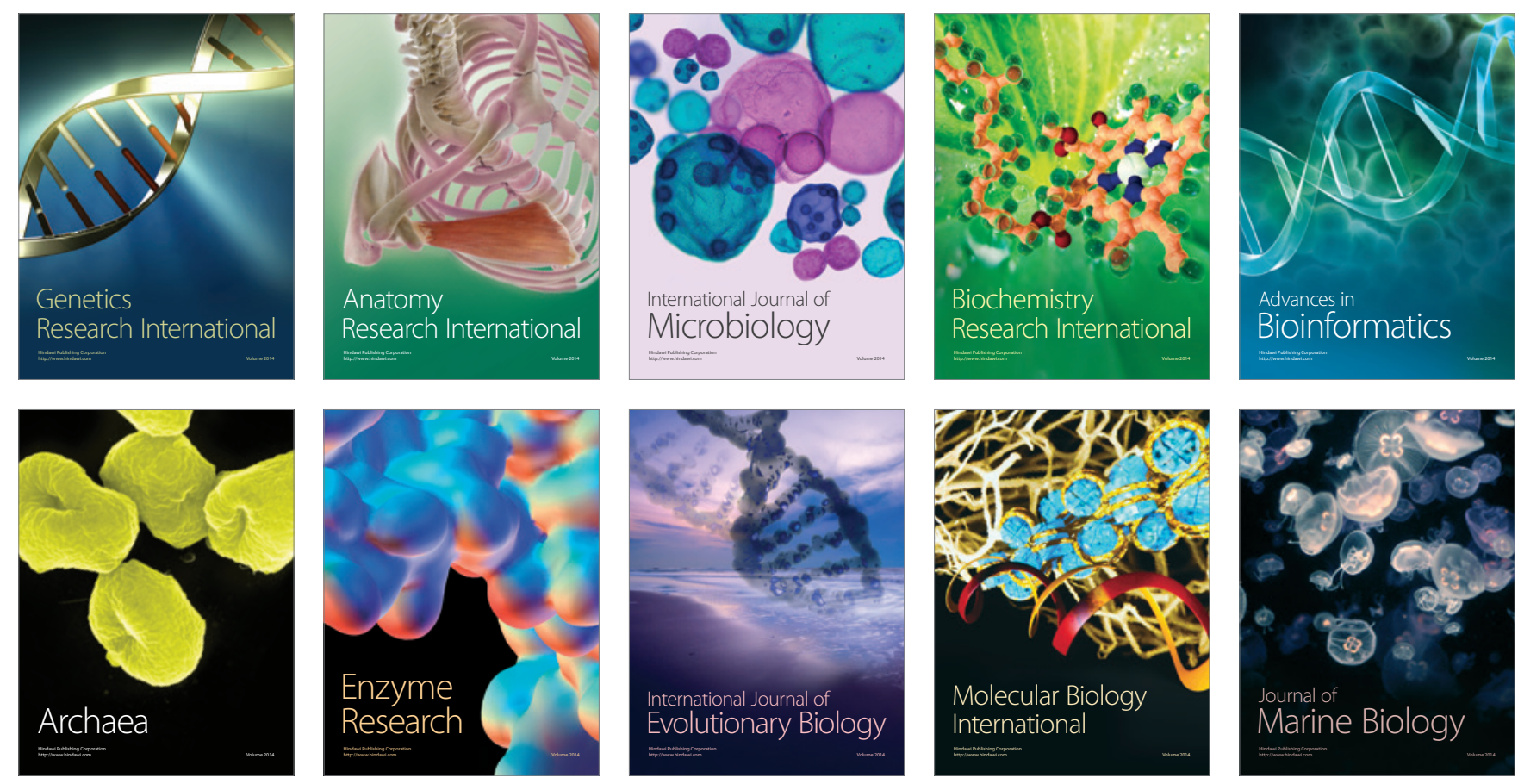